Supporting Information

\title{
Polar-Nonpolar Interfaces of Normal Bicontinuous Cubic Phases in Nonionic Surfactant/Water Systems are Parallel to Gyroid Surface
}

Toshihiko Oka ${ }^{1,2, *}$, Noboru Ohta ${ }^{3}$ and Stephen T. Hyde $e^{4,5}$

${ }^{1}$ Department of Physics, Faculty of Science and ${ }^{2}$ Nanomaterials Research Division, Research

Institute of Electronics, Shizuoka University, Shizuoka 422-8529, Japan

${ }^{3}$ SPring-8/JASRI, 1-1-1 Kouto, Sayo-cho, Sayo-gun, Hyogo 679-5198, Japan

${ }^{4}$ Department of Applied Mathematics, Research School of Physics and Engineering, Australian

National University, Canberra ACT 2601, Australia

${ }^{5}$ School of Chemistry, University of Sydney, New South Wales 2006, Australia

*Corresponding author: oka.toshihiko@shizuoka.ac.jp 
Table S1. Amplitudes of structure factors and parameters determined by X-ray diffraction measurements.

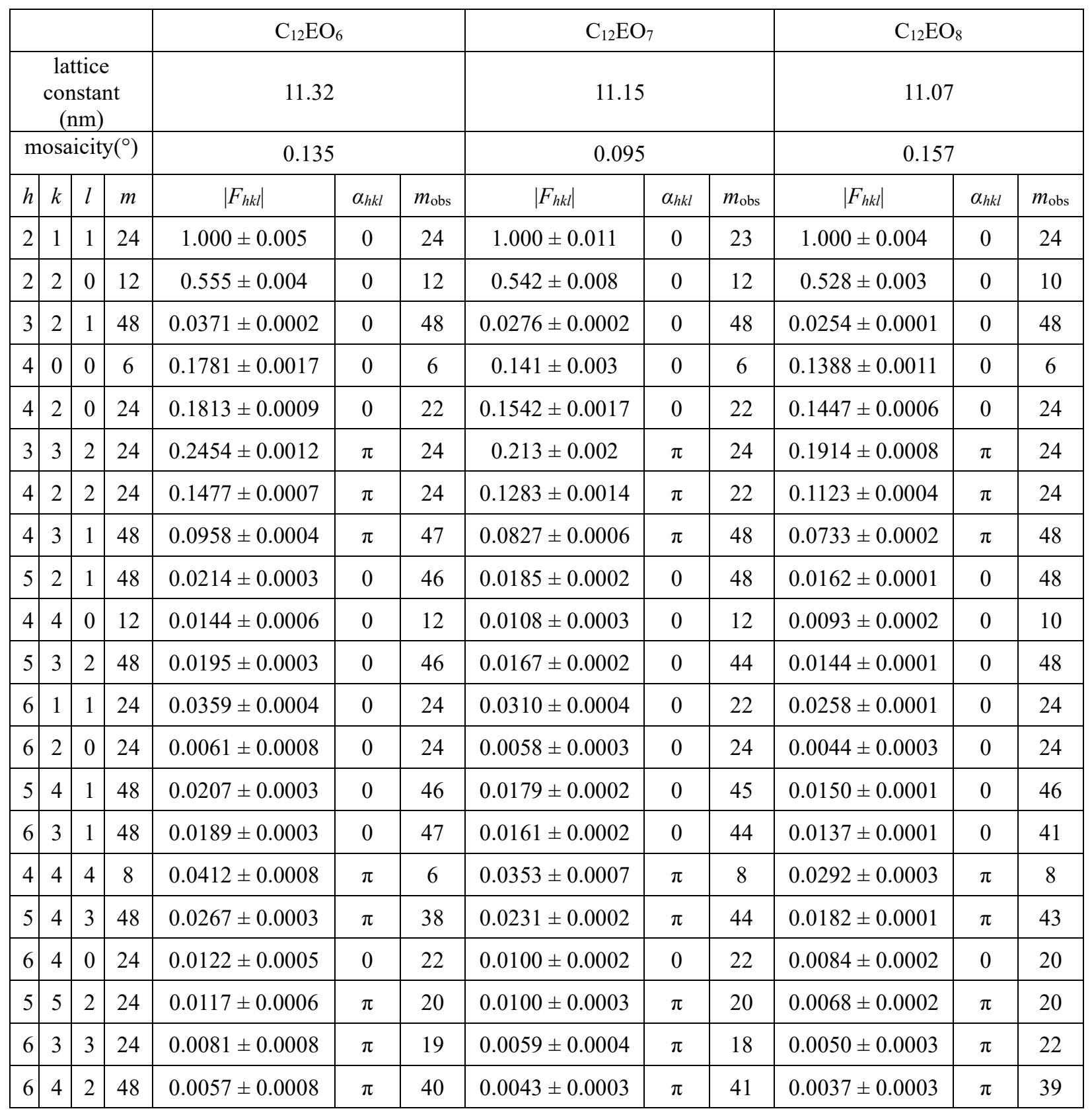

$h, k, l$ : Miller indeces, $m$ : multiplicity (the number of equivalent reflections), $\left|F_{h k l}\right|:$ absolute value of amplitude, $\alpha_{h k l}:$ phase, $m_{\mathrm{obs}}$ : the number of observed equivalent reflections

Phase were calculated from models (see text). 
Table S2. Optimized parameters of model functions.

\begin{tabular}{|c|c|c|c|c|c|c|c|c|}
\hline & model & $\rho_{2}$ & $\rho_{3}$ & $w_{1}{ }^{* *}$ & $w_{2}{ }^{* *}$ & $\sigma^{* *}$ & $\Delta F^{2}$ & $\begin{array}{c}R \\
\text { factor }\end{array}$ \\
\hline $\mathrm{C}_{12} \mathrm{EO}_{6}$ & PS & 20.5 & -13.0 & $\begin{array}{c}0.0343 \\
(0.388 \mathrm{~nm})\end{array}$ & $\begin{array}{c}0.0937 \\
(1.061 \mathrm{~nm})\end{array}$ & $\begin{array}{c}0.0577 \\
(0.653 \mathrm{~nm})\end{array}$ & 0.00096 & 0.046 \\
\cline { 2 - 8 } & $\mathrm{CMCS}$ & 6.50 & -17.8 & - & $\begin{array}{c}0.0623 \\
(0.705 \mathrm{~nm})\end{array}$ & $\begin{array}{c}0.0464 \\
(0.525 \mathrm{~nm})\end{array}$ & 0.0308 & 0.190 \\
\hline $\mathrm{C}_{12} \mathrm{EO}_{7}$ & PS & 17.1 & -14.7 & $\begin{array}{c}0.0345 \\
(0.384 \mathrm{~nm})\end{array}$ & $\begin{array}{c}0.0948 \\
(1.057 \mathrm{~nm})\end{array}$ & $\begin{array}{c}0.0586 \\
(0.653 \mathrm{~nm})\end{array}$ & 0.00047 & 0.036 \\
\hline $\mathrm{C}_{12} \mathrm{EO}_{8}$ & PS & 19.0 & -14.1 & $\begin{array}{c}0.0340 \\
(0.376 \mathrm{~nm})\end{array}$ & $\begin{array}{c}0.0929 \\
(1.028 \mathrm{~nm})\end{array}$ & $\begin{array}{c}0.0612 \\
(0.677 \mathrm{~nm})\end{array}$ & 0.00030 & 0.032 \\
\hline
\end{tabular}

*A volume fraction of hydrophobic regions is 0.28 .

**An edge length of a unit cell is 1 . The actual length is in parentheses. 


\section{(a)}

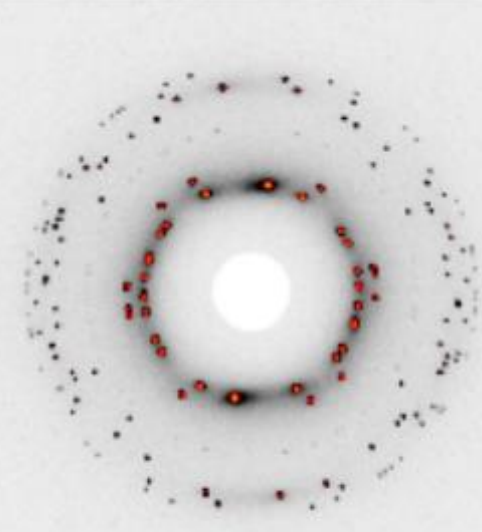

\section{(b)}

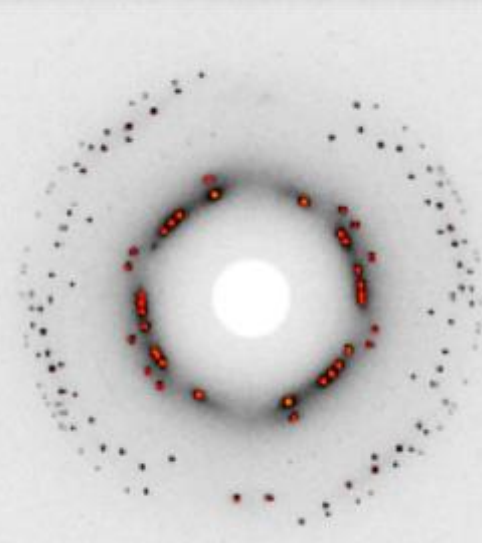

\section{(c)}
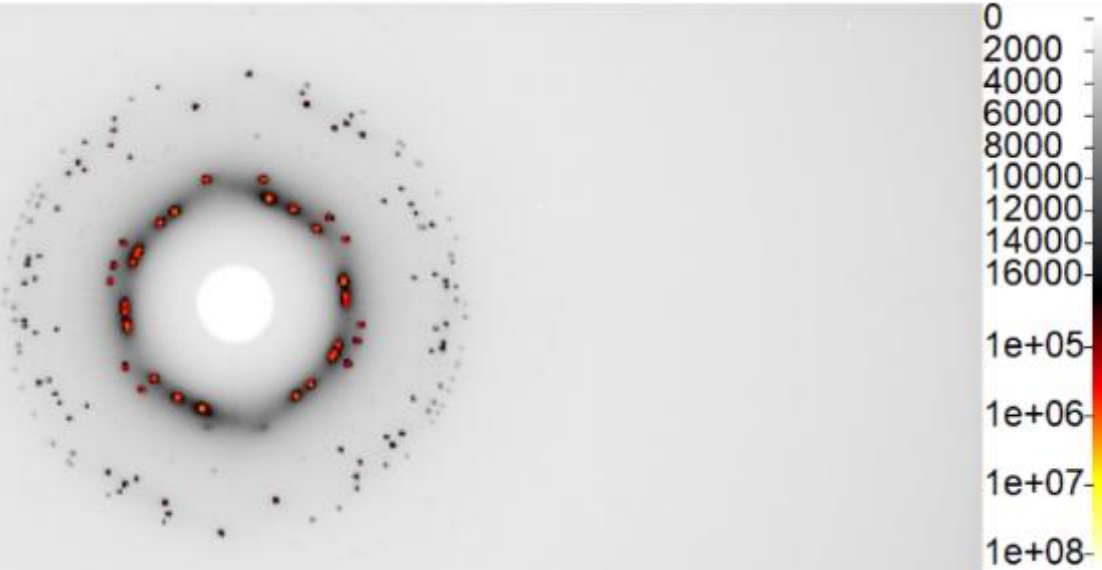

Figure S1. X-ray diffraction images summed over rotation angle of $180^{\circ}$. (a) $\mathrm{C}_{12} \mathrm{EO}_{6}$, (b) $\mathrm{C}_{12} \mathrm{EO}_{7}$, and (c) $\mathrm{C}_{12} \mathrm{EO}_{8}$. Figures were generated with Albula 3.2.0 (Dectris, Baden, Switzerland). 

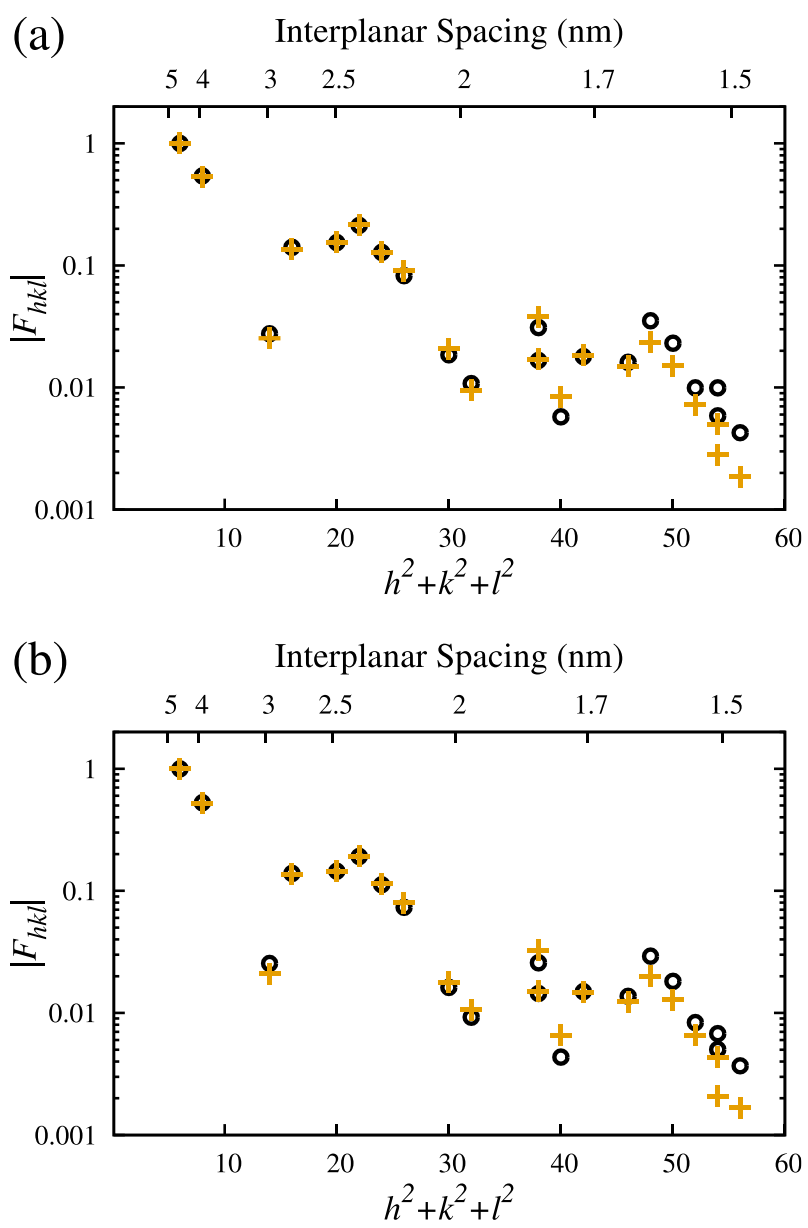

Figure S2. Amplitudes of structure factors, $\left|F_{h k l}\right|$, of (a) $\mathrm{C}_{12} \mathrm{EO}_{7}$ and (b) $\mathrm{C}_{12} \mathrm{EO}_{8}$. ( $h k l$ ) are Miller indices. Black circles are amplitudes determined by X-ray diffraction measurements. Orange pluses are amplitudes calculated from parallel surface models. 


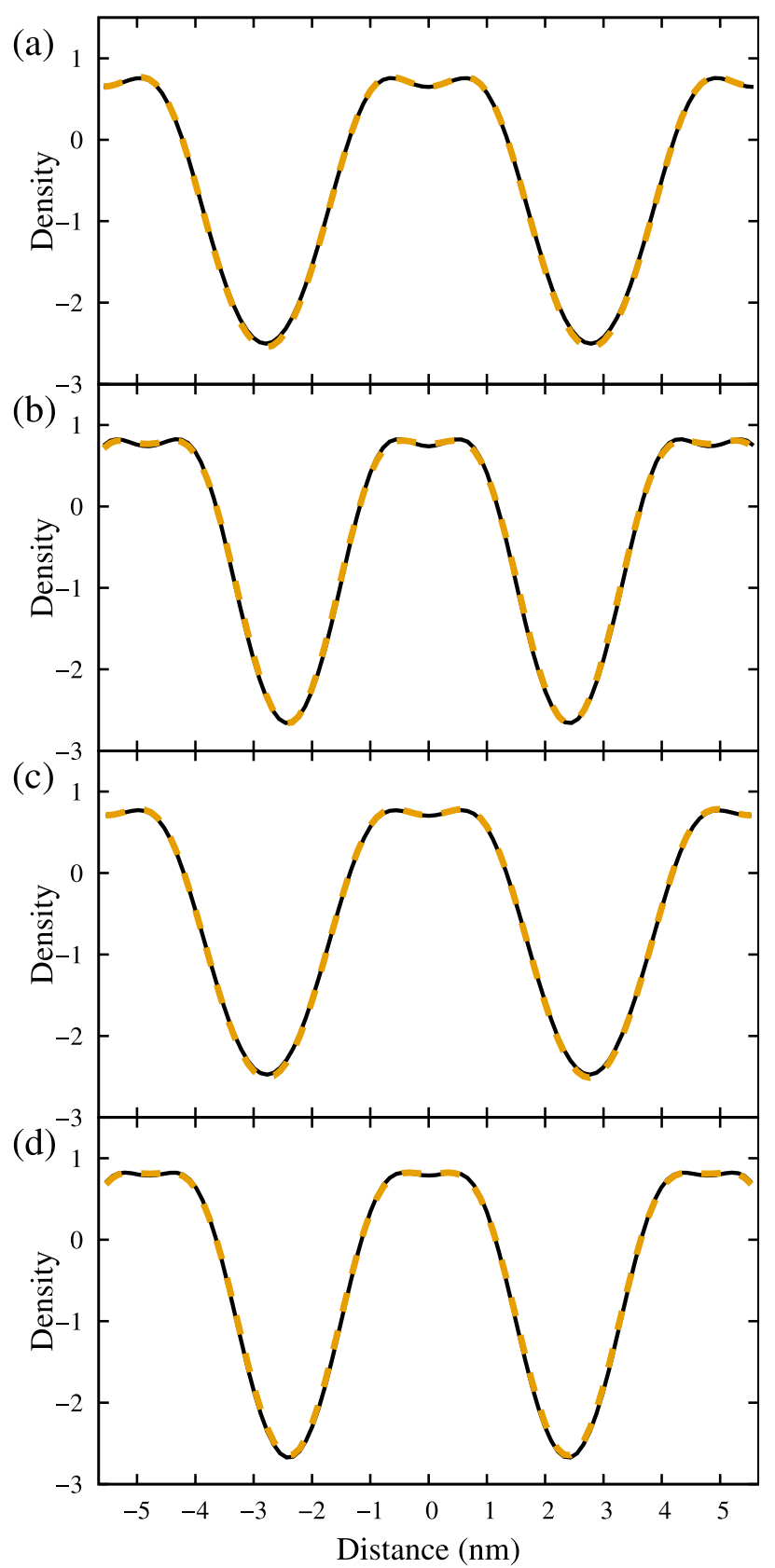

Figure S3. One-dimensional electron density distributions along straight lines corresponding to those in Figure 1 for (a-b) $\mathrm{C}_{12} \mathrm{EO}_{7}$ and (c-d) $\mathrm{C}_{12} \mathrm{EO}_{8}$. The lines follow the [100] direction in (a) and (c), and [111] in (b) and (d). The distance from the Gyroid is mapped on the horizontal axis. Black solid lines are density distributions from experimental data, while orange dashed lines are parallel surface models, respectively. 